\title{
Financial Inclusion and Macroeconomic Stability in Emerging and Frontier Markets
}

Complutense

de Análisis

Económico

\author{
Anh The Vo, Loan Thi-Hong Van, Duc Hong Vo \\ Business and Economics Research Group \\ Ho Chi Minh City Open University \\ Vietnam
}

\section{Michael McAleer}

Department of Finance Asia University, Taiwan

And Discipline of Business Analytics

University of Sydney Business School, Australia

And Econometric Institute, Erasmus School of Economics

Erasmus University Rotterdam, The Netherlands

And Department of Economic Analysis and ICAE

Complutense University of Madrid, Spain and

Institute of Advanced Sciences, Yokohama National University, Japan

\begin{abstract}
Financial inclusion, being considered as a key enabler to reducing poverty and boosting prosperity in emerging and frontier markets such as Vietnam, is the process in which individuals and small businesses are provided with an access to useful and affordable financial products and services. The extant literature on the empirical evidence regarding the contribution of financial inclusion to macroeconomic stability is mixed. This paper investigates the linkages between financial inclusion and macroeconomic stability, which has not yet been thoroughly examined in the literature, for 22 emerging and frontier economies from 2008 to 2015, with particular focus on a potential optimal level. Using the panel threshold estimation technique, the empirical findings show that financial inclusion, as approximated by the growth rate in the number of bank branches over 100,000 account holders, is found to enhance financial stability under a certain threshold. Financial inclusion is also found to be of benefit to maintaining stable inflation and output growth. Policy implications are also discussed on the basis of the important empirical findings.
\end{abstract}

Keywords Financial inclusion; Macroeconomic stability; Panel threshold; Emerging and frontier markets.
JEL Classification
C62, F65, 016, P45.

\section{Working Paper no 1901}

January, 2019 


\title{
Financial Inclusion and Macroeconomic Stability in Emerging and Frontier Markets*
}

\author{
Anh The Vo, Loan Thi-Hong Van, Duc Hong Vo \\ Business and Economics Research Group \\ Ho Chi Minh City Open University \\ Vietnam \\ Michael McAleer** \\ Department of Finance \\ Asia University, Taiwan \\ and \\ Discipline of Business Analytics \\ University of Sydney Business School, Australia \\ and \\ Econometric Institute, Erasmus School of Economics \\ Erasmus University Rotterdam, The Netherlands \\ and \\ Department of Economic Analysis and ICAE \\ Complutense University of Madrid, Spain \\ and \\ Institute of Advanced Sciences, Yokohama National University, Japan
}

Revised: December 2018

* The authors are most grateful to Chia-Lin Chang for helpful discussions, comments and suggestions. For financial support, the first three authors acknowledge the National Foundation for Science and Technology Development, Vietnam, and the fourth author thanks the Australian Research Council and Ministry of Science and Technology (MOST), Taiwan.

** Corresponding author: michael.mcaleer@gmail.com 


\begin{abstract}
Financial inclusion, being considered as a key enabler to reducing poverty and boosting prosperity in emerging and frontier markets such as Vietnam, is the process in which individuals and small businesses are provided with an access to useful and affordable financial products and services. The extant literature on the empirical evidence regarding the contribution of financial inclusion to macroeconomic stability is mixed. This paper investigates the linkages between financial inclusion and macroeconomic stability, which has not yet been thoroughly examined in the literature, for 22 emerging and frontier economies from 2008 to 2015, with particular focus on a potential optimal level. Using the panel threshold estimation technique, the empirical findings show that financial inclusion, as approximated by the growth rate in the number of bank branches over 100,000 account holders, is found to enhance financial stability under a certain threshold. Financial inclusion is also found to be of benefit to maintaining stable inflation and output growth. Policy implications are also discussed on the basis of the important empirical findings.
\end{abstract}

Keywords: Financial inclusion; Macroeconomic stability; Panel threshold; Emerging and frontier markets.

JEL: C62, F65, O16, P45. 


\section{Introduction}

In recent years, many countries worldwide have been pursuing financial inclusion, an expansion of financial systems, financial services, or financial products to approach every single user in the economy. Statistics show that more than 60 nations have been recorded as setting financial inclusion as a formal goal (Sahay et al., 2015). The fundamental implication of financial inclusion is to provide an equal opportunity to access financial services to low-income households and small firms.

Financial inclusion helps to broaden a financial network and create an efficient financial flow within country's borders. In addition, financial inclusion tends to make the availability of formal financial services (such as deposit and saving accounts, payment services, loans, and insurance) for the use of customers so that they can fulfill their demand actively and effectively. All functions of financial inclusion are expected to improve the personal well-being of individuals, reduce poverty sand enhance economic growth and development (Sahay et al., 2015).

A related but distinct term from financial inclusion is financial development, which is closely associated with macro-level indicators, such as the size of the stock market or the ratio of domestic credit to a country's gross domestic product (GDP). Financial inclusion is typically measured via the number of people who own and use formal financial products (Kapper, ElZoghbi and Hess, 2016). Many factors impact both the level of financial inclusion and financial development within a country, such as per capita income, good governance, quality of institutions, availability of information, and the regulatory environment (En et al., 2012; Park and Mercado, 2015).

It might be argued that extended financial services in a country may introduce potential instability into a market. Garcia (2016) raised the important issue that there might be an associated link between financial inclusion and financial stability. The author argued that an unregulated financial system and rapid credit growth caused by financial inclusion and its instruments might inherently lead to greater risks in financial markets. 
The key lessons from the 2007-2009 Global Financial Crisis are closely associated with systematic financial risks, so that policy makers and regulators have made great efforts to maintain financial stability (Cihak, Mare and Melecky, 2016; Morgan and Pontines, 2018). For the pre-crisis period, in virtually all emerging and developed countries, banks proposed to lend to risky borrowers. Negative aspects of expanding finance availability appear to be a trigger waiting for the collapse of the financial system.

However, a counterpoint is that risks posed by financial inclusion are hardly systemic due to the fact that low-income individuals are likely to keep their financial behaviour as usual, even though financial crashes. Savers retain their deposits, while borrowers pay back their loans (Hannig and Jansen, 2010). Financial inclusion supplements financial services to each and every individual in the economy. This implies that broader access to deposits would diversify the deposit base, thereby improving the resilience of the overall financial system and enhancing the stability of the national economy.

Furthermore, financial inclusion acts as a supporting source of finance, providing small and medium firms with the working capital, and thus promoting and enabling these businesses to perform more efficiently. These two opposite debates raise an important issue as to how financial inclusion or financial expansion might affect macroeconomic stability. In this sense, the link between financial inclusion and macroeconomic stability is a matter of considerable importance, especially in emerging markets, where the overall financial system remains relatively underdeveloped.

Although financial inclusion has progressed in recent years, and has been perceived to have a positive impact on economic growth and development, its effects on macroeconomic factors and stability seem inadequate (Sahay et al., 2015). This paper provides empirical evidence regarding the impact of financial inclusion on macroeconomic stability. Previous studies have found evidence that an expansion for access to credit without appropriate supervision would lead to an increase in financial risk (Sahay et al., 2015). This paper argues that there may be an optimal level of financial inclusion that enhances macroeconomic stability, which has not yet been 
investigated in the existing literature. Moreover, to the best of our knowledge, few studies have investigated the impact of financial inclusion on inflation and output volatility.

A notable exception is Mehrotra and Yetman (2014), which shows that a higher degree of financial inclusion leads to an increase in the ratio of output volatility to inflation volatility. However, the authors did not separate the impact of financial inclusion on each key and fundamental indicator. This paper provides empirical evidence to fill this research gap, and contributes to the insights regarding the linkages between financial inclusion and the volatility of inflation and output.

The structure of the remainder of the paper is as follows. Section 2 reviews the relevant theoretical and empirical studies in the literature. Section 3 presents the research methodology to be used in the empirical analysis. Data and novel empirical findings are presented in Section 4, followed by some concluding remarks in Section 5 .

\section{Literature Review}

The linkages between financial inclusion and macroeconomic stability have not yet been thoroughly examined in the literature. We follow an existing strand of the literature that has linked financial inclusion and financial instability or economic volatility.

On the one hand, financial inclusion has been found to be negatively related to macroeconomic stability, either by increasing financial risks or by reducing macroeconomic stability. Morgan and Pontines (2018) considered that financial inclusion expanded a range of borrowers, lowering lending standards and conditions, and consequently raising economic and financial risks. An increase in lending to micro-finance institutions without appropriate supervision could impair the total effectiveness of the regulations in a country, thereby raising risks in the financial system as a whole. Mehrotra and Yetman (2015) asserted that excessive access to credit could deteriorate the credit quality and accelerate unregulated credit growth. 
On the other hand, there are several channels explaining the positive linkages between financial inclusion and macroeconomic stability. The first is to enhance the intermediation between savings and investment more effectively. Financial inclusion not only provides financial institutions with a broader spectrum of economic agents, with a greater diversification of their assets, but also with an economy of resilience (Khan, 2011). Greater lending to small firms would lower the overall risks that a bank would encounter. Morgan and Pontines (2018) found an increased share of small- to medium-sized enterprises (SMEs) leads to a decrease in financial instability by reducing non-performing loans and the associated probability of default or bankruptcy.

Moreover, financial inclusion would result in a more extensive and efficient savings intermediation, and provide a more stable base of retail deposits (Morgan and Pontines, 2018). Low-income savers and lenders tend to maintain their financial behaviour during financial crises, keeping their deposits in a safe place and paying off their loans (Hannig and Jansen, 2010).

In addition, financial inclusion restricts the presence of a large informal sector, which could limit the effectiveness of national monetary policy (Garcia, 2016). Furthermore, Mehrotra and Yetman (2015) documented that an increase in financial inclusion can smooth consumption as households have greater opportunities to approach financial services for their savings and borrowings. This development causes a reduction in output volatility, and an increase in price stability from the central bank.

Numerous empirical studies have been conducted over the years. However, most studies have focused on financial or bank stability rather than macroeconomic stability. For example, Ahamed and Mallick (2017) have investigated the effects of financial inclusion on bank stability using an international sample of 2,600 banks from 86 nations. A bank employs the inclusive financial system to raise its low interest deposit. Consequently, the bank can benefit from reducing the marginal costs of funding, and taking advantage of its pricing power in the money market. As a result, the bank is likely to stabilize its financial system through the implementation of financial inclusion. 
Such empirical results lend support to the fact that higher levels of financial inclusion would lead to greater bank stability. The positive relationship is particularly found in banks with higher customer deposit funding shares, with lower marginal costs of providing banking services, and within countries experiencing good quality institution. The impact of financial inclusion varies differently across measures of bank stability. Morgan and Pontines (2018) also found inconsistent findings on the relationship between financial inclusion and financial stability by two different measures of financial inclusion.

Han and Melecky (2013) analyzed the relationship between expanding deposits and the volatility of bank deposit growth, and found that there is a close positive link between greater deposits and the resilience of the financial systems during the financial crisis period. This empirical finding appears to be consistent with the theory of monetary policy that central banks tend to force the banking system to withdraw money from the market to reduce a heated performance during financial distress periods.

Neaime and Gaysset (2017) addressed the impact of financial inclusion on a wide range of factors from income inequality and poverty to financial stability using MENA countries for the analysis. The MENA region possesses a significant growth rate, and a well-established financial system, but a widely segmented population, in general. The empirical results show that financial inclusion is found to be negatively associated with income inequality, positively related with financial stability, and have no definitive conclusion.

Cihak et al. (2016) provided evidence on a trade-off relation between financial stability and financial inclusion. The degree of trade-off or synergy depends greatly, not only on the indicators that measure financial stability and inclusion, but also on their estimated covariances. Without the crisis, financial inclusion tends to be positively correlated with financial stability.

It should be noted that there is an exisiting link among macroeconomic stability variables. Fernandez, Gonzalez, and Suarez (2016) presented the impact of bank stability on economic volatility. The authors argued that bank development helps reduce the internal risks of firms through supporting working capital for investment. However, financial intermediaries amplify 
macroeconomic shocks to individual firms through imperfect capital markets. Creel, Hubert, and Labondance (2015) examined the impact of financial stability on economic performance, from both microeconomic and macroeconomic perspectives, for countries that are in the European Union.

Micro-prudential policies help limit bankruptcy risks and abnormal risks for firms, while macroprudential policies aim to minimize the probability of financial crisis and systematic risks for the whole economy. A striking point is that authors have used various indecators of financial instability, based not only on previous studies, but also their own measures derived from principle components analysis, despite several indicators of economic performance, such as GPD per capita, consumption per capita, disposiable income per capita, and investment being taken into consideration. Overall, the empirical results reveal negative effects of financial instability on economic performance.

The association of financial inclusion and individual well-being has also been investigated in empirical studies. For example, using data of nearly 800 financial institutions regarding financial inclusion, as measured by lending to rural borrowers, Lopez and Winkler (2018) examined whether there are differences between the impacts of sustainability challenges on financial inclusion in rural and urban areas. Sustainability challenges are more likely to happen in rural areas owing to the presence of poverty, thereby resulting in higher transaction costs, larger risks, and more disadvantageous contracting conditions. When financial inclusion is considered as the use of financial services, it would loosen individual financial constraints from investments to their own favour, such as education for business purposes.

Fungacova and Weill (2014) suggest that SMEs and individuals in China who face tight constraints on accessing formal credit are likely to turn to alternative sources, for example, from friends and relatives, and even from informal lenders. This leads to an expansion of shadow banking, which woulds in turns deteriorate the effectiveness of bank regulations and cause instability in the market. The authors also examine other Asian countries to examine alternative sources of borrowing. The authors conclude that the motives for individuals who turn to financial 
inclusion is mainly a lack of funding, such that the most commonly-used method of informal borrowings is by borrowing from acquaintances.

\section{Methodology}

Based on arguments and evidence from empirical studies, we formulate a regression model in order to explore the financial inclusion - macroeconomic stability nexus, as follows:

$$
Y_{i t}=\alpha_{i}+\beta F I_{i t}+\gamma_{j} Z_{j t}+\varepsilon_{i t}
$$

where the dependent variable $\left(Y_{i t}\right)$ represents macroeconomic stability. Five proxies that are used to measure macroeconomic stability include: (i) bank Z-score, (ii) the ratio of non-performing loan (NPL) to gross loan, (iii) NPL provision, (iv) inflation volatility, and (v) output growth volatility.

The Bank Z-score measures the probability to default of a country's banking system, which is calculated as follows:

$$
\text { Bank } Z-\text { score }=\frac{R O A+(\text { equity/assets })}{s d(R O A)}
$$

where $R O A$ is the return of assets and $s d(R O A)$ is the standard deviation of asset returns.

The Bank Z-score has been widely used in several studies as an indicator of financial stability see (Han and Melecky, 2013, Creel et al., 2015, Cihak et al., 2016, Ahamed and Mallick, 2017, among others). In general, the Bank Z-score simply captures the standardized return of a country’s bank system. In short, for each standard deviation that faces volatility, this measures how much the whole bank system can afford to earn or lose. A more instable financial system can lead to lower financial returns overall. The annual volatility of inflation and output growth are calculated as the standard deviation of the monthly changes in the consumer price index and the industrial price index, respectively. 
The independent variable $(X)$ consists of financial inclusion $\left(F I_{i t}\right)$, measured by the growth rate in the numbers of bank branches over 100,000 account holders and control variables $\left(Z_{j t}\right)$, which include per capita GDP growth, the logarithm of real GDP, exchange rate volatility, fixed exchange rate regime, financial openness, and liquid asset to GDP. The coefficient $\gamma_{j}$ is the vector of nuisance parameters, and $\varepsilon_{i, t}$ is the random error term, while $i=1, \ldots, 22$ represents the countries and $t=2008, \ldots, 2015$ denotes the time period. The coefficient $\beta$ is of interest as it shows the impact of financial inclusion on macroeconomic stability. Equation (1) is estimated using panel ordinary least squares (OLS) estimation.

In order to distinguish the appropriate relationship between financial inclusion and financial stability, Ahamed and Mallick (2017) and Morgan and Pontiners (2018) consider some macroeconomic indicators, such as the GDP growth rate, GDP per capita, and financial openness. Using another approach, Cihak et al. (2016) used non-parameter tests to examine the effects of macro factors on the relationship between financial inclusion and financial stability. Their empirical findings indicate that a firm's progressing duration, financial openness, fiscal regulations, and restrictions on investment significantly affect the correlation between the two elements of interest.

However, throughout the literature survey, we have not observed any research that has used macro risks, such as inflation, or monetary policy, such as exchange rate policy, to control for systematic risk and policy risk. Hence, this paper uses the following approximations, namely inflation as macro systematic risk, exchange rate volatility as international finance risk, and a fixed exchange rate regime as a policy risk.

GDP growth is expected to be positively correlated with macroeconomic instability. Increased risks and financial imbalances are often pro-cyclical because the risks might be underestimated when investors are overly optimistic regarding their future economic prospects. Another factor associating with macroeconomic stability is the size of the economy (Fouejieu, 2017; Morgan and Pontines, 2018). It is hypothesized that larger economies are more financially developed, and more closely integrated into the international financial system, and hence are more vulnerable to 
internal and external financial shocks. Therefore, the effect of the size of the economy on financial instability is expected to be positive (Morgan and Pontines, 2018).

The inflation rate is also expected to promote macroeconomic instability. Increasing the inflation rate is usually accompanied by higher inflation volatility, greater uncertainty in the economy, and blurs expectations. Rising inflation can be perceived as a sign of deterioration in economic stability (Neaime and Gayset, 2017). Exchange rate volatility increases uncertainty on foreign currency that denominates transactions. In this regard, higher exchange rate volatility would be associated with higher currency risks for financial institutions, and increasing risks for the financial system as a whole (Fouejieu, 2017).

With a fixed exchange rate regime, there is no clear intuition regarding the expected effect of this variable on macroeconomic instability as the literature leads to a variety of conclusions. Earlier studies (Rogoff et al., 2004) argue in favour of a bipolar view, suggesting that the hard peg and pure floating regimes are less prone to financial instability than intermediate regimes. A recent empirical analysis by Ghosh, Ostry and Qureshi (2014) reveals that macroeconomic and financial instability are significantly greater in less flexible regimes (including hard pegs) relative to pure floating regimes.

The ratio of liquid assets to deposits and short-term funding is a measure of the liquidity of the asset base, which should be positively correlated with financial stability. Similarly, financial openness, and the ratio of the sum of overseas financial assets and liabilities to GDP, also measures the susceptibility to volatile capital flows (Morgan and Pontines, 2018).

It should be noted that the impact of financial inclusion on macroeconomic stability might happen under a certain level of financial inclusion. The paper therefore adopts the panel threshold estimation technique, introduced by Hansen (1999). This method allows the sample to be divided into different groups based on the level of financial inclusion. Following Hansen (1999), we rewrite equation (1) as follows: 


$$
Y_{i t}=\left\{\begin{array}{l}
\alpha_{i}+\beta_{1} F I_{i t}+\gamma_{j} Z_{j t}+\varepsilon_{i t} ; F I_{i t} \leq \theta \\
\alpha_{i}+\beta_{2} F I_{i t}+\gamma_{j} Z_{j t}+\varepsilon_{i t} ; F I_{i t}>\theta
\end{array}\right.
$$

In order to check whether the threshold effect is statistically significant, we test the hypothesis of the difference between $\beta_{1}$ and $\beta_{2}$ using $F$-statistic test, as established in Hansen (1999). If the estimated threshold variable of financial inclusion is significant, it may be concluded that there are different impacts of financial inclusion on macroeconomic stability between lower and higher estimated values of $\theta$.

\section{Data and Empirical Results}

\subsection{Data}

The data used in the paper is obtained primarily from the Global Financial Development Database of (GFDD) by the World Bank, and International Financial Statistics (IFS) by the International Monetary Fund. Three measures of macroeconomic stability, namely the Bank Zscore, the ratio of NPL to gross loan, and NPL provision, are collected from the GFDD while the other two, the volatility of inflation and output growth, are calculated according to the monthly data of the consumer price index and industrial price index from IFS. The main regressor of financial inclusion, as approximated by the number of bank branches over 100,000 adults, is from GFDD. The variable mainly reflects the supply side of financial inclusion, indicating the real accessibility to finance. In terms of the demand side, the indicators are available in the Global Findex by World Bank.

However, this database is only possible for two separate years, namely 2011 and 2014. Moreover, our study just focuses on emerging and frontier economies, with a sample size of 22 countries. The lack of time periods raises difficulties in processing panel analysis. If crosscountry estimation is proposed, we still face a highly non-robust result due to inadequacy in the number of observations. This paper has sacrificed a little representative ability of the financial inclusion variable for a more robust empirical test in terms of developing an optimal data set, as far as possible. Therefore, the data set includes 22 emerging and frontier economies from 2008 to 2015, as shown in Table 1. The statistical description of all the variables is shown in Table 2. 


\section{[Tables 1 and 2 go here]}

\subsection{Empirical results}

Table 3 shows that financial inclusion has a positive impact on macroeconomic stability. The coefficients of this variable all are found to be statistically significant at the lower threshold of the growth rates of the numbers of bank branches. Over the threshold, all coefficients have negative signs, but are insignificant. Furthermore, the results reveal a significant negative impact of financial inclusion on inflation volatility and output growth volatility. The threshold values of the growth rates of the numbers of bank branches range between 0.033 and 0.063 for most of the independent variables. An interesting and exceptional case is output volatility, which has a threshold value of 0.25 , but only when the case of the Bank Z score is found to be significant at the $10 \%$ level.

These empirical results imply that an increase in the number of bank branches within an optimal level would lead to a lower probability of default of financial institutions (Bank Z score), an improvement in the NPL loans over gross loan and NPL provision, as well as the prevention of volatility in inflation and output growth. The empirical finding also gains support from Sahay et al. (2015)'s analysis, which illustrates that financial inclusion with adequate supervision and regulation will reduce instability in economic growth. According to Mehrotra and Yetman (2014), with a high degree of financial inclusion, central banks would set the optimal monetary policy to balance the trade-off between output volatility and inflation volatility, with greater focus being placed on inflation.

Moreover, the results are in favour of the view that promoting financial inclusion, especially limiting the growth rate in the numbers of bank branches at an optimal level, would supplement the stability in the macroeconomic environment, as suggested by Cihak et al. (2016). The empirical findings in this paper are fairly consistent with those in Ahamed and Mallick (2017), who find positive impacts of financial inclusion on the banking system internationally. 


\section{[Table 3 goes here]}

In analyzing the impact of control variables on macroeconomic stability, the estimates of the Bank Z-score show that per capita GDP growth has a positive impact on macroeconomic stability, while the real GDP has a reverse pattern. It is expected that inflation has a negative impact on macroeconomic stability, but the results are less supportive. Higher inflation is found to have positive and significant effect on inflation volatility. Although a fixed exchange rate regime is expected to improve the stability of a macroeconomic environment, it seems to play a relatively minor role in maintaining macroeconomic stability. Exchange rate volatility and financial openness appear to have a negative impact on macroeconomic stability in the estimation of the Bank Z-score, and other cases provide little empirical evidence either way.

\section{Concluding Remarks}

This paper provided empirical evidence on the linkages between financial inclusion and macroeconomic stability for emerging and frontier markets. It was hypothesized that there may be an optimal level of financial inclusion that enhances macroeconomic stability, which has not yet been investigated in the existing literature. The panel threshold estimation method was used to determine the optimal level. We used a balanced panel data of 22 emerging and frontier countries, where the data were available, over the 2008-2015 time period. Various indicators of macroeconomic stability (such as the Bank Z-score, NPL to gross loans, and provision to NPL, inflation volatility and output growth volatility were adopted in the examination of the potential effects of financial inclusion on macroeconomic stability.

\section{[Figure 1 goes here]}

The empirical findings in this paper indicated that financial inclusion, as approximated by the growth rate in the number of bank branches over the 100,000 account holders, was found to enhance financial stability under a certain threshold, and that above the threshold, the relationship was reversed. Financial inclusion was also found to be beneficial in restricting inflation and output growth stability. Other potential macroeconomic variables, such as inflation, 
exchange rate volatility, and financial openness, provided mixed results in explaining macroeconomic stability.

Important policy implications have emerged from our analysis, in particular for Vietnam, a rising star in economic growth in the Asia-Pacific region. With 3.5 bank branches per 100,000 adults and an annual growth rate of only 2 per cent, Vietnam still has a long way to achieve an optimal level in comparison with other ASEAN countries, as presented in Figure 1. The strategy of pursuing a fixed exchange rate regime did not register any increased impact on macroeconomic stability.

Although the empirical findings appear to support the promotion of financial inclusion, as measured by the growth rate in the numbers of bank branches, as it had a great benefit in retaining macroeconomic stability, its profound impact could be extended to other aspects of an economy, such as alleviating poverty, boosting economic growth, and increasing the well-being of individuals and households. Bruhn and Love (2014) used a natural experiment in Mexico to investigate the impact of the opening of new commercial banks and increased access to credit on low-income individuals. The authors documented the benefits of opening new commercial banks for citizens in Mexico.

Increased access to financial services would lead to an improvement in income levels, a higher degree of investment on informal business, and a lower unemployment rate overall. Some existing research has focused on the impact of financial inclusion on income inequality and economic growth (Kim, Yu and Hassan, 2018; Kim, 2016; Park and Mercado, 2015; Turegano and Herrero, 2018), and the well-being of households (Swamy, 2014; Zhang and Posso, 2017). Most of these studies have adopted cross-section data for the empirical analysis. Empirical research on related issues using panel data and associated methodology and techniques would be worth performing in the future. 


\section{References}

Ahamed, MM and SK Mallick (2017). Is financial inclusion good for bank stability? International evidence. Journal of Economic Behavior and Organization.

Bruhn, M, I Love (2014). The real impact of improved access to finance: Evidence from Mexico. The Journal of Finance, 69(3), 1347-1376.

Camara, N and D Tuesta (2014). Measuring financial inclusion: A muldimensional index.

Cihak, M, DS Mare and M Melecky (2016). The nexus of financial inclusion and financial stability: A study of trade-offs and synergies.

Creel, J, P Hubert and F Labondance (2015). Financial stability and economic performance. Economic Modelling, 48, 25-40.

En, F, A Demirguc-Kunt, L Klapper and MS Peria (2012). The foundations of financial inclusion: Understanding ownership and use of formal accounts.

Fernández, AI, F Gonzalez and N Suarez (2016). Banking stability, competition, and economic volatility. Journal of Financial Stability, 22, 101-120.

Fungacova, Z and L Weill (2014). A view on financial inclusion in Asian countries.

Fouejieu, A (2017). Inflation targeting and financial stability in emerging markets. Economic Modelling, 60, 51-70.

Garcia, MJR (2016). Can financial inclusion and financial stability go hand in hand? Economic -Issues, 21(2), 81-103.

Ghosh, AR, JD Ostry and MS Qureshi (2014). Exchange rate management and crisis susceptibility: A reassessment. IMF working paper No 14/11.

Han, R and M Melecky (2013). Financial inclusion for financial stability: Access to bank deposits and the growth of deposits in the global financial crisis.

Hannig, A and S Jansen (2010). Financial inclusion and financial stability: Current policy issues.

Hansen, BE (1999). Threshold effects in non-dynamic panels: Estimation, testing, and inference. Journal of Econometrics, 93(2), 345-368. 
Khan, H. R. (2011). Financial inclusion and financial stability: are they two sides of the same coin? Address by Shri HR Khan, Deputy Governor of the Reserve Bank of India, at BANCON 2011, organized by the Indian Bankers Association and Indian Overseas Bank, Chennai, 4 November 2011.

Kim, DW, JS Yu and MK Hassan (2018). Financial inclusion and economic growth in OIC countries. Research in International Business and Finance, 43, 1-14.

Kim, JH (2016). A study on the effect of financial inclusion on the relationship between income inequality and economic growth. Emerging Markets Finance and Trade, 52(2), 498-512.

Klapper, L, M El-Zoghbi and J Hess (2016). Achieving the sustainable development goals - The role of financial inclusion.

Lopez, T and A Winkler (2018). The challenge of rural financial inclusion-evidence from microfinance. Applied Economics, 50(14), 1555-1577.

Mehrotra, A and J Yetman (2015). Financial inclusion-issues for central banks. BIS Quarterly Review.

Mehrotra, A and J Yetman (2014). Financial inclusion and optimal monetary policy. BIS Working Paper, No. 476.

Mialou, A, G Amidzic and A Massara (2017). Assessing countries' financial inclusion standing-A new composite index. Journal of Banking and Financial Economics, 8(2), $105-126$.

Morgan, P and V Pontines (2018). Financial stability and financial inclusion: The case of SME lending. The Singapore Economic Review, 63(1), 111-124.

Morgan, PJ and Y Zhang (2017). Mortgage lending, banking crises, and financial stability in Asia and Europe. Asia Europe Journal, 15(4), 463-482.

Neaime, S and I Gaysset (2017). Financial inclusion and stability in MENA: Evidence from poverty and inequality. Finance Research Letters, 24, 230-237.

Park, CY and RV Mercado (2015). Financial inclusion, poverty, income inequality in developing Asia. Asian Development Bank Economics Working Paper No. 426. Manila: Asian Development Bank.

Rogoff, R, A Husain, AMody, R Brooks, N Oomes (2004). Evolution and performance of exchange rate regimes. IMF Occasional Working Paper, No. 229. 
Sahay, R, M Cihak, P N’Diaye, A Barajas, S Mitra, A Kyobe, SR Yousefi (2015). Financial inclusion: can it meet multiple macroeconomic goals?

Swamy, V (2014). Financial inclusion, gender dimension, and economic impact on poor households. World Development, 56, 1-15.

Turegano, DM and AG Herrero (2018). Financial inclusion, rather than size, is the key to tackling income inequality. The Singapore Economic Review, 63(1), 167-184.

Zhang, Q and A Posso (2017). Thinking inside the Box: A closer look at financial inclusion and household income. Journal of Development Studies, 1-16. 


\section{Table 1}

\section{Selected Countries}

\begin{tabular}{ll}
\hline Country group & Country \\
\hline Emerging countries & Brazil, Chile, Colombia, Czech Republic, Egypt, India, Korea, \\
& Mexico, Pakistan, Peru, Poland, Russian Federation, South Africa, \\
& Turkey, Indonesia, Philippines, Malaysia, Thailand. \\
\hline Frontier & Croatia, Jordan, Kuwait, Nigeria \\
\hline
\end{tabular}




\section{Table 2}

\section{Summary Statistics}

\begin{tabular}{lccccc}
\hline Variables & Observation & Mean & Std. Dev. & Min & Max \\
\hline Z score & 176 & 11.67 & 6.55 & 2.63 & 33.45 \\
NPL-loan ratio & 176 & 5.14 & 4.47 & 0.48 & 37.30 \\
NPL provision & 176 & 78.12 & 42.19 & 26.90 & 200.65 \\
Inflation volatility & 176 & 0.49 & 0.33 & 0.07 & 2.23 \\
Output volatility & 144 & 6.53 & 2.16 & 1.38 & 12.55 \\
Financial inclusion & 176 & 20.62 & 29.61 & 4.45 & 257.70 \\
GDPPC growth & 176 & 1.85 & 3.31 & -12.57 & 9.47 \\
Ln(GDP) & 176 & 5.90 & 1.08 & 3.20 & 7.79 \\
Inflation & 176 & 5.40 & 3.87 & -0.99 & 20.29 \\
ER volatility & 176 & 2.94 & 2.06 & 0.47 & 9.93 \\
Regime & 176 & 0.43 & 0.50 & 0.00 & 1.00 \\
Capital openness & 176 & 0.36 & 1.21 & -1.19 & 2.37 \\
Liquid asset over funding & 176 & 25.86 & 12.58 & 7.55 & 66.70 \\
\hline
\end{tabular}




\section{Table 3}

\section{Panel Threshold Estimates}

\begin{tabular}{|c|c|c|c|c|c|}
\hline & Z scores & NPL-loan ratio & NPL provision & $\begin{array}{l}\text { Inflation } \\
\text { volatility }\end{array}$ & $\begin{array}{c}\text { Output } \\
\text { volatility }\end{array}$ \\
\hline \multirow[t]{2}{*}{ GDPPC growth } & $0.075^{* *}$ & -0.028 & 0.437 & 0.006 & 0.050 \\
\hline & $(0.038)$ & $(0.088)$ & $(0.353)$ & $(0.006)$ & $(0.044)$ \\
\hline \multirow[t]{2}{*}{ Ln(GDP) } & $-2.197^{*}$ & $-7.572 * *$ & -17.006 & $-0.421^{* *}$ & -0.361 \\
\hline & (1.233) & (2.941) & (11.386) & $(0.208)$ & (1.366) \\
\hline \multirow[t]{2}{*}{ Inflation } & -0.042 & -0.078 & 0.166 & $0.050 * * *$ & -0.048 \\
\hline & $(0.045)$ & $(0.104)$ & $(0.418)$ & $(0.007)$ & $(0.050)$ \\
\hline Exchange rate & $-0.158 * * *$ & 0.087 & -0.206 & 0.012 & 0.066 \\
\hline Volatility & $(0.060)$ & (0.139) & $(0.560)$ & $(0.010)$ & $(0.064)$ \\
\hline \multirow[t]{2}{*}{ Regime } & 0.451 & 1.700 & -5.700 & 0.047 & -0.735 \\
\hline & $(0.467)$ & (1.089) & (4.377) & $(0.077)$ & $(0.515)$ \\
\hline \multirow[t]{2}{*}{ Capital Openness } & $-0.754 * * *$ & $0.856^{*}$ & 0.468 & 0.033 & 0.149 \\
\hline & $(0.212)$ & $(0.493)$ & (1.964) & $(0.035)$ & $(0.315)$ \\
\hline Liquid asset over & -0.020 & -0.053 & $-0.319 *$ & 0.003 & -0.047 \\
\hline funding & $(0.020)$ & $(0.045)$ & $(0.185)$ & $(0.003)$ & $(0.030)$ \\
\hline \multirow[t]{2}{*}{ FI - Threshold 0} & $10.547 * *$ & $28.514^{* *}$ & $64.565 *$ & $-1.372 *$ & $-7.566 * * *$ \\
\hline & $(4.276)$ & (11.657) & $(36.200)$ & $(0.817)$ & $(2.745)$ \\
\hline \multirow[t]{2}{*}{ FI - Threshold 1} & -0.716 & -2.508 & $-20.848^{*}$ & 0.088 & -0.744 \\
\hline & $(1.220)$ & $(2.816)$ & (11.355) & $(0.199)$ & (1.273) \\
\hline \multirow[t]{2}{*}{ Constant } & $25.789 * * *$ & $50.483^{* * *}$ & $188.095^{* * *}$ & $2.532 * *$ & 10.185 \\
\hline & (7.449) & (17.704) & (68.803) & (1.255) & (8.448) \\
\hline Threshold value & $0.046^{*}$ & 0.033 & 0.063 & 0.035 & 0.25 \\
\hline F-test & 7.73 & 7.16 & 6.2 & 3.75 & 7.63 \\
\hline Observations & 176 & 176 & 176 & 176 & 144 \\
\hline R-squared & 0.223 & 0.155 & 0.097 & 0.409 & 0.134 \\
\hline Countries & 22 & 22 & 22 & 22 & 18 \\
\hline
\end{tabular}

Notes: $* * *, * * *$ indicates the significant coefficients at the $1 \%, 5 \%$, and $10 \%$ levels, respectively. The dependent variables, macroeconomic stability, are measured by Bank-Z score, NPL to gross loan (\%), and Provision to NPL (\%). The financial inclusion (FI) shows the estimates under the threshold value. 


\section{Figure 1}

\section{Breakdown of numbers of bank branches in selected ASEAN countries}
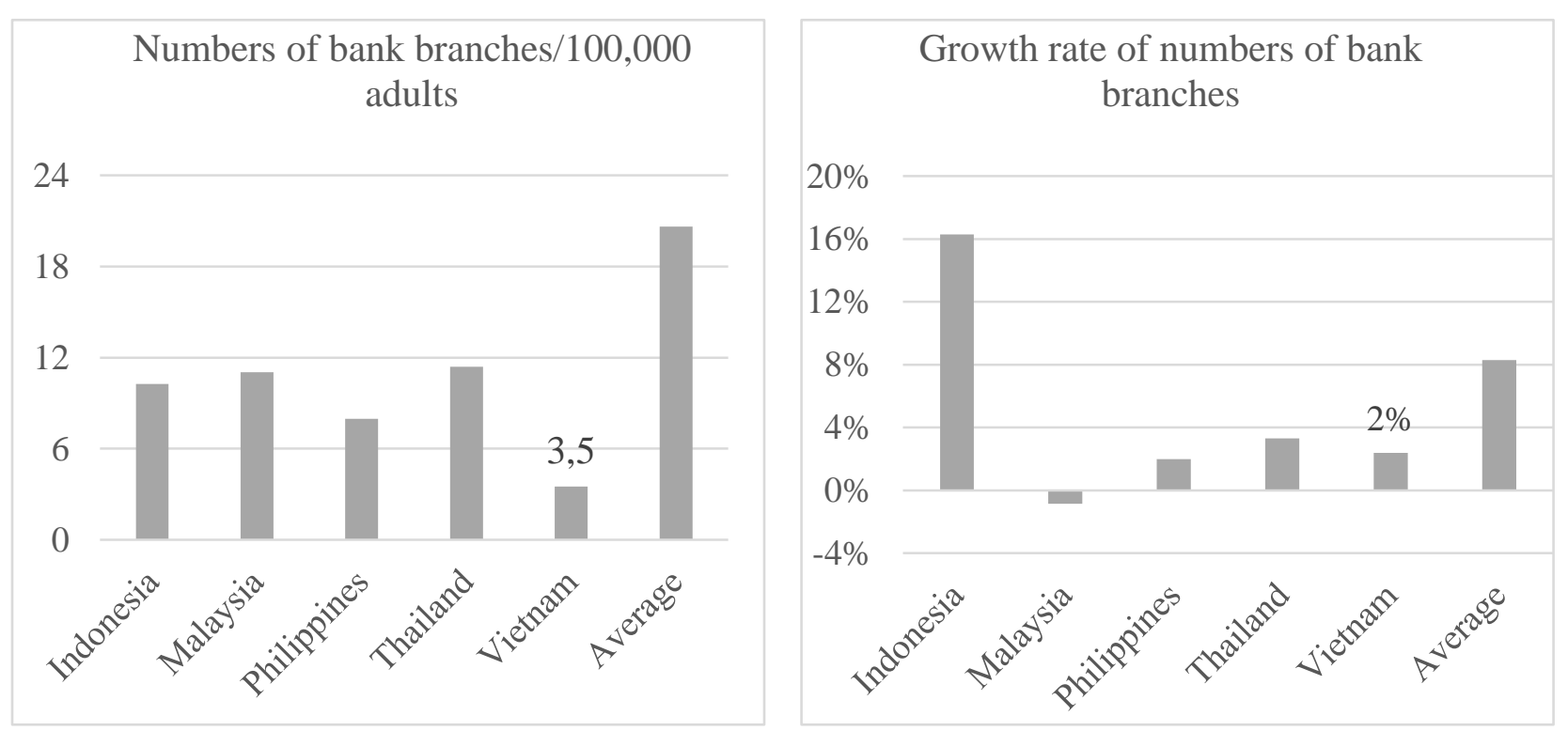